\title{
A SIMPLE WAY TO UPGRADE A COMPACT RADIOCARBON AMS FACILITY FOR ${ }^{10} \mathrm{Be}$
}

\author{
Arnold Milenko Müller ${ }^{1,2}$ - Martin Suter ${ }^{1} \bullet$ Dongpo Fu ${ }^{3}$ Xingfang Ding ${ }^{3}$ Kexin Liu K $^{3}$ \\ Hans-Arno Synal ${ }^{1} \cdot$ Liping Zhou $^{4}$
}

ABSTRACT. A simple way to upgrade the Peking University $500 \mathrm{kV}$ NEC radiocarbon facility (CAMS) for ${ }^{10} \mathrm{Be}$ measurements is presented. In a first phase, a silicon nitride foil as passive boron degrader was mounted in front of the electrostatic deflector near the focal plane of ${ }^{10} \mathrm{Be}$. The Si detector at the end of the beam line was replaced with a high-resolution $\Delta \mathrm{E}-\mathrm{E}_{\text {res }}$ gas ionization chamber. In addition, a Faraday cup for the measurement of ${ }^{9} \mathrm{Be}^{1+}$ was installed. Tests with this arrangement showed promising results: a ${ }^{10} \mathrm{Be} /{ }^{9} \mathrm{Be}$ background level of $3.4 \times 10^{-14}$ and an overall transmission for ${ }^{10} \mathrm{Be}$ of $2.2 \%$ were obtained. Measurements of standards showed very good stability and reproducibility. In the next step, it is planned to add a second magnet to reduce the background and to partly compensate losses due to energy and angular straggling in the degrader foil by the energy and angular refocusing effect of a magnetic sector field. With this final arrangement, a performance with ${ }^{10} \mathrm{Be} /{ }^{9} \mathrm{Be}$ background levels at $10^{-15}$ and ${ }^{10} \mathrm{Be}$ overall transmission of $6-7 \%$ can be expected. The design proposed in this paper has the advantage that the modifications can be realized in a rather inexpensive way and that the measurement performance for ${ }^{14} \mathrm{C}$ will not be affected.

\section{INTRODUCTION}

In recent years, many compact accelerator mass spectrometry (AMS) facilities operating at terminal voltages of $1 \mathrm{MV}$ or below have been installed for radiocarbon measurements. Besides ${ }^{14} \mathrm{C}$, the most important radionuclide measured with AMS is ${ }^{10} \mathrm{Be}$ (Fink 2010). The ETH AMS group has demonstrated that instruments with voltages of $500 \mathrm{kV}$ are sufficient to perform ${ }^{10} \mathrm{Be}$ measurements (Müller et al. 2010a,b), if the most advanced technology for gas ionization detectors is used and the intensity of the interfering ${ }^{10} \mathrm{~B}$ is reduced by the degrader foil method (Raisbeck et al. 1984) using very homogenous silicon nitride foils (Müller et al. 2008). The accelerator companies NEC and HVEE offer compact systems that have the potential to measure ${ }^{10} \mathrm{Be}$ (Klein et al. 2006, 2007; Norton and Klody 2011). In this paper, we discuss a simple way to upgrade the dedicated compact ${ }^{14} \mathrm{C}$ facility from NEC at Peking University (PKU, Liu et al. 2007) for ${ }^{10} \mathrm{Be}$ measurements and show the results of feasibility tests as well as the design for the final arrangement. In general, all other compact NEC AMS systems could be updated in a similar fashion.

\section{INSTRUMENTATION}

The compact AMS system (CAMS) for ${ }^{14} \mathrm{C}$ detection manufactured by NEC, e.g. the Poznan (Goslar et al. 2004) or Woods Hole (Roberts et al. 2004) system, is based on a prototype developed in a collaboration of NEC with ETH (Suter et al. 1999; Synal et al. 2000). This prototype demonstrated that ${ }^{14} \mathrm{C}$ dating is possible at low energies. The commercial NEC instrument differs significantly in the design from the ETH prototype: The ETH low-energy (LE) spectrometer consists of a $90^{\circ}$ bend-

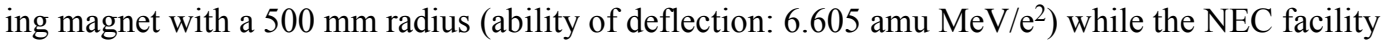

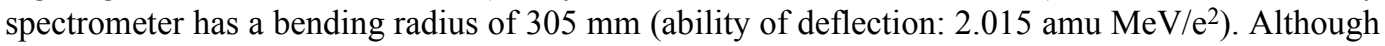
the ability of deflection is about 3 times smaller for the NEC spectrometer, the magnet is still strong enough to bend ${ }^{10} \mathrm{BeO}^{-}$with a maximal ion source energy of $65 \mathrm{keV}$.

\footnotetext{
${ }^{1}$ Laboratory of Ion Beam Physics, ETH Zurich, 8093 Zurich, Switzerland.

${ }^{2}$ Corresponding author. Email: arnold.mueller@phys.ethz.ch.

${ }^{3}$ State Key Laboratory of Nuclear Physics and Technology and Institute of Heavy Ion Physics, Peking University, Beijing 100871, China.

${ }^{4}$ Department of Geography, Peking University, Beijing 100871, China.
} 


\section{A M Müller et al.}

The NEC bouncer system with positive polarity allows quasi-simultaneous measurement of ${ }^{12} \mathrm{C}$ and ${ }^{13} \mathrm{C}$ currents both on the low-energy (LE) and high-energy (HE) side. The LE Faraday cup is mounted inside the accelerator tank at the position of ${ }^{13} \mathrm{C}^{-}$, when injecting mass 14 in the accelerator. The isotopic mass ratio in the case of $\mathrm{BeO}(26 / 25)$ is smaller than that of $\mathrm{C}$, leading to a smaller deflection for ${ }^{9} \mathrm{BeO}^{-}$. There is not enough space for an additional cup between the LE cup and the ion optical axis of the accelerator. Thus, measurement of the ${ }^{9} \mathrm{Be}$ beam transmission will require a bipolar bouncing supply or application of a bias voltage on the magnet chamber. During our test, no bipolar bouncer power supply was available and the operation in a biased mode was not configured. It was therefore not possible to measure the transmission continuously during an automatic measurement. Nevertheless, the ${ }^{9} \mathrm{Be}$ transmission could be determined sequentially by changing the field of the LE magnet to direct ${ }^{9} \mathrm{BeO}^{-}$into the $\mathrm{LE}$ cup before and after an automated ${ }^{10} \mathrm{Be} /{ }^{9} \mathrm{Be}$ measurement.

In contrast to the ETH facility, the Pelletron charging system of the PKU NEC system is mounted on the LE side of the tank. This leads to a different arrangement of the NEC HE spectrometer containing the HE Faraday cups. Since the distance between the center of the stripper canal and the entrance of the magnetic spectrometer is significantly smaller than in the ETH system, the focal distances of the HE spectrometers are different. Therefore, the ETH arrangement for ${ }^{10} \mathrm{Be}$ could not be copied directly. Ion optics calculations were made for carbon first to understand the ion optics of the instrument in the original configuration. The calculations for the ${ }^{10} \mathrm{Be}$ beam transport were performed using Weick's GICOSY code (http://web-docs.gsi.de/ weick/gicosy/) and the ETHIonOptics program (Suter et al. 2010). The beam transport for $\mathrm{Be}^{1+}$ differs significantly from that of $\mathrm{C}^{1+}$ because of the molecular breakup of $\mathrm{BeO}^{-}$in the stripper. The phase space compression and focusing by the HE acceleration tube is stronger compared to carbon (Stocker et al. 2004). For this reason, the ${ }^{10} \mathrm{Be}$ focus is at roughly the position of the ${ }^{13} \mathrm{C}$ cup (Figure 1), about $30 \mathrm{~cm}$ closer to the HE magnet than the ${ }^{14} \mathrm{C}$ focus.

The silicon nitride degrader foil (thickness $75 \mathrm{~nm}$; area $8 \times 6 \mathrm{~mm}^{2}$ ) needed to reduce the interfering ${ }^{10} \mathrm{~B}$ current can be mounted on a metal plate attached to the electron suppressor aperture of the ${ }^{13} \mathrm{C}$ cup. The cup's 1-inch micrometer feed-through was replaced by a 2-inch version, so that either the ${ }^{13} \mathrm{C}$ cup can be put in position with the SiN foil out of the beam or the foil can be moved into the beam position for the ${ }^{10} \mathrm{Be}$ measurements. In addition, a new Faraday cup for ${ }^{9} \mathrm{Be}^{1+}$ has been mounted on an unused flange between the ${ }^{12} \mathrm{C}$ and ${ }^{13} \mathrm{C}$ cup (Figure 1 ) and connected to the ${ }^{13} \mathrm{C}$ current integrator. With this setup, no changes on the vacuum housing were needed.

For the first experiments, the beam line components for ${ }^{14} \mathrm{C}$ detection after the electrostatic deflector (ESA) were removed as a whole (Faraday cup, beam profile monitor, and the Si detector) and replaced by a $\Delta \mathrm{E}-\mathrm{E}_{\text {res }}$ gas ionization detector designed and built at ETH (Suter et al. 2007; Müller et al. 2010a, 2012). A SiN entrance window of $4 \times 4 \mathrm{~mm}^{2}$ size and $30 \mathrm{~nm}$ thickness was used. This detector in combination with the CoolFET ${ }^{\circledR}$ preamplifiers (Amptek Inc., USA) provides optimal resolution for the separation of ${ }^{10} \mathrm{Be}$ and ${ }^{10} \mathrm{~B}$.

After installation of the gas ionization chamber at the PKU beam line, the detector performance was tested first with a 2-parameter data acquisition system, the MPA3 Multiparameter Multichannel Analyzer (FAST ComTec GmbH, Germany). For all other tests, the $\mathrm{E}_{\text {res }}$ signal was the input to the 1-dimensional data NEC acquisition system. The $\triangle \mathrm{E}$ signal was fed to a single-channel analyzer (SCA) with a window set on the ${ }^{10} \mathrm{Be}$ signal. The output of this SCA was then used as a trigger for the data acquisition, leading to a simplified $\Delta \mathrm{E}-\mathrm{E}_{\text {res }}$ spectrum. 


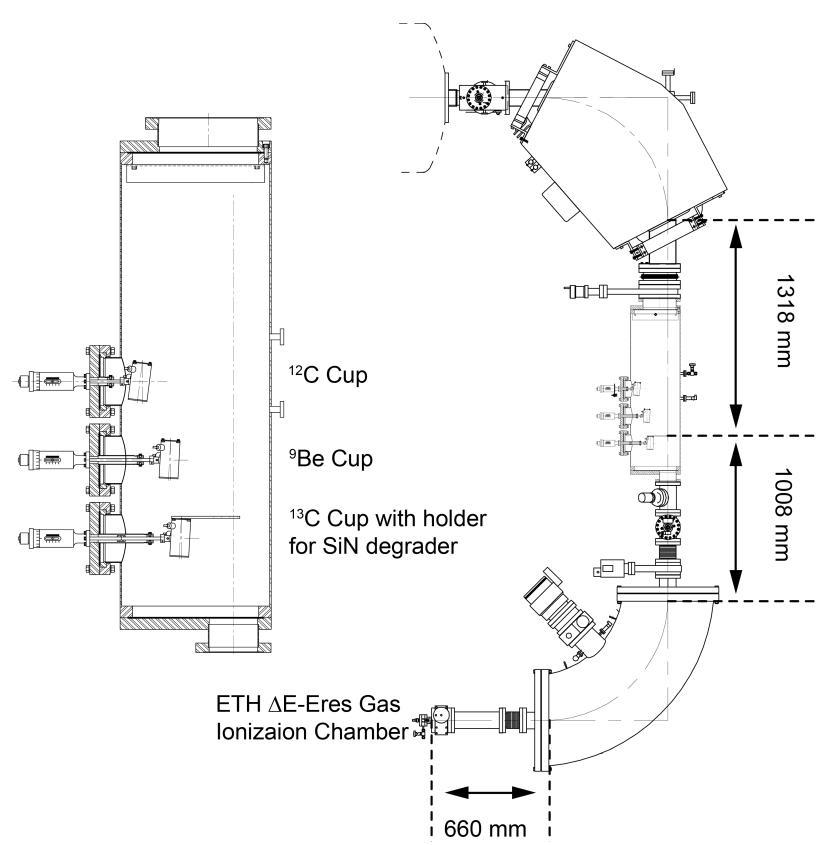

Figure 1 High-energy section of the compact AMS facility at Peking University with the modifications made for the ${ }^{10} \mathrm{Be}$ test measurements: Faraday cup for ${ }^{9} \mathrm{Be}$ current measurement and holder for the silicon nitride foil attached to the ${ }^{13} \mathrm{C}$ cup. This cup is mounted on a 2-inch-long $\mu \mathrm{m}$ feedthrough allowing to position alternatively the cup (during ${ }^{14} \mathrm{C}$ measurements) or the degrader foil for the boron suppression. For the test measurements, the position of the detector was $\sim 10 \mathrm{~cm}$ behind the ${ }^{10} \mathrm{Be}$ focal plane in order to use the existing beam line.

\section{RESULTS}

The test measurements were performed with the terminal voltage and the source potential set to the ${ }^{14} \mathrm{C}$ values (Table 1). Optimal settings were found with scans for various parameters such as field values (LE and HE magnet, ESA) and positions of the foil and vertical position of the detector. Some of these scans were made with ${ }^{10} \mathrm{~B}$ first, then the transmission for ${ }^{10} \mathrm{Be}$ was optimized. Measurements with ${ }^{10} \mathrm{Be}$ in charge state $1+$ and $2+$ obtained from the foil showed that ${ }^{10} \mathrm{Be}^{1+}$ produced a better background rejection with about the same stripping yield as ${ }^{10} \mathrm{Be}^{2+}$. The gas pressure (isobutane) in the detector was adjusted to obtain the best possible isobar suppression (Figure 2).

An automatic measurement series was made with 9 NIST standard samples $\left({ }^{10} \mathrm{Be} /{ }^{9} \mathrm{Be}: 26.8 \times 10^{-12}\right)$ to test the stability of the system. Additionally, 8 in-house low-level standards with a ${ }^{10} \mathrm{Be} /{ }^{9} \mathrm{Be}$ nominal ratio of $1.4 \times 10^{-14}$ were measured to estimate the background level. Test parameters are listed in Table 1. The average sample measurement time was about $30 \mathrm{~min}$ for the high-level standards and 100 min for the low-level standards.

The measured ${ }^{10} \mathrm{Be} /{ }^{9} \mathrm{Be}$ ratio of the NIST standard is much lower than the nominal value of the standard because of beam losses due to energy and angular straggling and post-stripping processes in the $\mathrm{SiN}$ degrader foil (Müller et al. 2010b). The observed raw ratio of $1.17 \times 10^{-12}$ corresponds to a ${ }^{10} \mathrm{Be}$ transmission of $4.4 \%$ through the degrader foil into the detector. Only a rough quantitative analysis of the different processes can be given at this point. 
Figure 2 2D-spectrum of a ${ }^{10} \mathrm{Be}$ standard sample measured with the ETH-built gas ionization detector. The energy of the beam entering the detector was $\sim 620 \mathrm{keV}$. The entrance window of the detector is a $4 \times 4 \mathrm{~mm}^{2}$ SiN membrane of $30 \mathrm{~nm}$ thickness. The separation power of the detector is good enough to clearly identify boron and beryllium events.

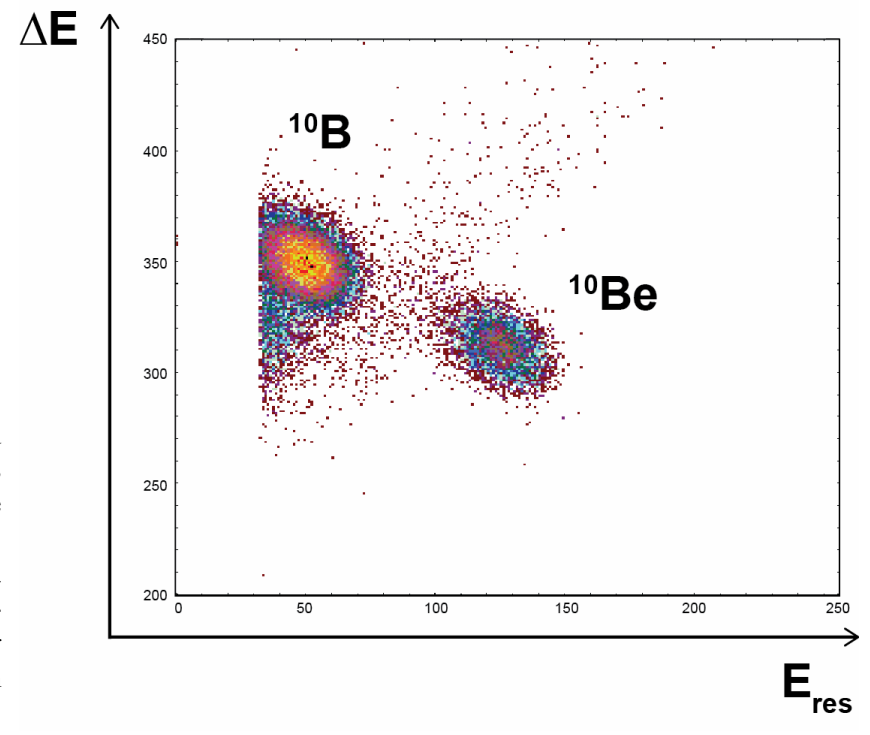

Table 1 Operating conditions and performance.

\begin{tabular}{ll}
\hline Source energy & $57 \mathrm{keV}$ \\
Terminal voltage & $470 \mathrm{kV}$ \\
Total energy ${ }^{10} \mathrm{Be}$ & $708 \mathrm{keV}$ \\
Energy after foil & $672 \mathrm{keV}$ \\
Typical ${ }^{9} \mathrm{BeO}-$ current of standard & $0.3-1.4 \mu \mathrm{A}$ \\
Transmission ${ }^{9} \mathrm{Be}$ & $\sim 50 \%$ \\
Transmission ${ }^{10} \mathrm{Be}$ to detector & $\sim 2 \%$ \\
Background & ${ }^{10} \mathrm{Be} /{ }^{9} \mathrm{Be}: 3.5 \times 10^{-14}$ \\
\hline
\end{tabular}

The charge state distribution for ${ }^{10} \mathrm{Be}$ passing the SiN degrader is not well known. According to previous measurements performed at ETH (Müller et al. 2010b), and since the yield for the 1+ and 2+ charge state is almost at the same level, the yield must be $<50 \%$. The detector was centered on the ${ }^{10} \mathrm{Be}$ energy peak. According to Sun et al. (2007), the energy straggling in the $75-\mathrm{nm} \mathrm{SiN}$ window for ${ }^{10} \mathrm{Be}$ at $708 \mathrm{keV}$ is $\sim 8 \mathrm{keV}$ (FWHM). The $4 \times 4 \mathrm{~mm}^{2}$ entrance window used corresponds to an energy acceptance of $2 \mathrm{keV}$, which includes $\sim 23 \%$ of the energy distribution. The residual loss is caused by limitations of the beam transport due to angular straggling in the SiN window and the initial phase space of the beam entering the degrader foil (angular acceptance of the ESA: 20 mrad). Taking the ${ }^{9} \mathrm{Be}$ transmission of $\sim 50 \%$ through the accelerator into account (determined manually before the automatic measurements), an overall transport yield for ${ }^{10} \mathrm{Be}$ of $\sim 2.2 \%$ was reached. A statistical uncertainty of $0.59 \%$ and standard deviation of $0.67 \%$ for the 9 NIST standard samples are indications of high measurement stability.

The measured raw ratio of the in-house low-level standards was $1.5 \times 10^{-15}$. Taking the losses due to the SiN degrader into account, a ${ }^{10} \mathrm{Be} /{ }^{9} \mathrm{Be}$ background level of $3.4 \times 10^{-14}$ with a statistical uncertainty of $10 \%$ was achieved, which would be already sufficient for many applications. At ETH, the background was at $1 \times 10^{-13}$ without the additional magnet. One explanation for the smaller background level of the NEC system is that fewer ${ }^{9} \mathrm{Be}$ ions are reaching the detector because of better vacuum conditions in the high-energy acceleration tube (Müller et al. 2008). Since the accelerator tank of the NEC system is turned $180^{\circ}$ relative to the ETH setup, the distance between stripper and 
Way to Upgrade Compact ${ }^{14} \mathrm{C}$ AMS Facility for ${ }^{10} \mathrm{Be}$

the turbopump at the high-energy end of the accelerator is much shorter and the pumping of the acceleration tube is therefore more efficient.

\section{Final Arrangement}

Based on the experience gained at ETH, an additional magnet can significantly reduce the background and increase the ${ }^{10} \mathrm{Be}$ transmission to the detector (Müller et al. 2010b). It is planned to add such a magnet with a radius of $35 \mathrm{~cm}$ and a deflection of $90^{\circ}$ (Figure 3). The magnet will provide a field strong enough to bend ${ }^{10} \mathrm{Be}$ ions at charge $2+$ as well as charge $1+$ (ability of deflection: $7.15 \mathrm{amu} \mathrm{MeV} / \mathrm{e}^{2}$ ). For ${ }^{14} \mathrm{C}$, which is routinely measured at energies of $\sim 1 \mathrm{MeV}$ in the $1+$ charge state, the bending power will not be sufficient. With adjustable slits, which will be placed in the intermediate focal plane, the accepted energy window can be adjusted to optimize ${ }^{10} \mathrm{Be}$ transmission and keep the ${ }^{10} \mathrm{~B}$ rate as low as possible. Assuming an asymmetric aperture of $4 \mathrm{~mm}$ on the "boron side" of the beam ( $2 \mathrm{keV}$ energy acceptance) and $15 \mathrm{~mm}$ on the opposite side ( $7.4 \mathrm{keV}$ energy acceptance), $70 \%$ of ${ }^{10} \mathrm{Be}$ energy distribution would be covered. The ESA magnet arrangement does not form a strict achromatic system. However, the second magnet will have an energy focusing effect, so that most of the ${ }^{10} \mathrm{Be}$ can be detected in the final chamber, if the detector entrance window is wide enough $(\sim 8 \mathrm{~mm})$. Thus, ${ }^{10} \mathrm{Be}$ transmission to the detector will be enhanced by a factor of $\sim 3$. A removable holder for the $\mathrm{Si}$ detector will be constructed and placed in front of the additional magnet so that the ${ }^{14} \mathrm{C}$ measurements can be performed as before.

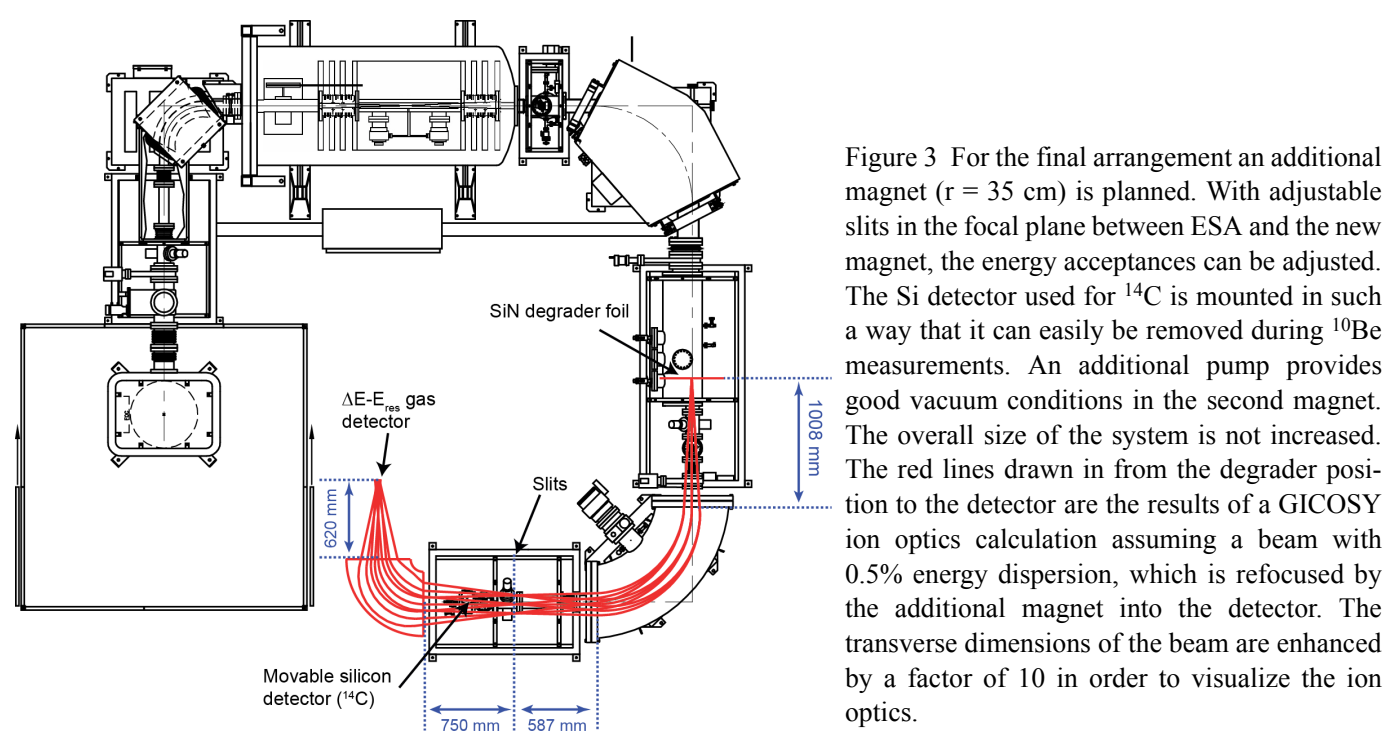

The software provided by NEC has to be adapted to allow for 2-dimensional spectra. The hardware for the data acquisition does not need any modification; a 16-channel peak ADC (Philips 7164) is already incorporated in the system. Also, some minor modifications are needed on the bouncer control system, so that ${ }^{9} \mathrm{Be}$ can be measured in the offset Faraday cup at the LE side. Based on the experience at ETH in Zurich, it is expected that with this modified arrangement the background at PKU can be reduced to a level of about $10^{-15}$ and that the transmission for ${ }^{10} \mathrm{Be}$ can reach $6-7 \%$. 


\section{A M Müller et al.}

\section{CONCLUSIONS}

We have presented here a simple arrangement for measuring ${ }^{10} \mathrm{Be}$ with a compact AMS system from $\mathrm{NEC}$ designed for ${ }^{14} \mathrm{C}$ measurements. Just by adding a $\triangle \mathrm{E}-\mathrm{E}_{\text {res }}$ gas ionization detector and a $\mathrm{SiN}$ degrader foil to an existing CAMS system, a ${ }^{10} \mathrm{Be} /{ }^{9} \mathrm{Be}$ background level of $3.5 \times 10^{-14}$ has been reached, which is sufficient for many applications. By upgrading the system with an additional $90^{\circ}$ magnet, a significant improvement of the ${ }^{10} \mathrm{Be}$ transmission and background is expected without affecting the performance of the ${ }^{14} \mathrm{C}$ measurements. The modified setup is significantly smaller than the present version manufactured by NEC for ${ }^{10} \mathrm{Be}$ (Norton and Klody 2011). Our design might be considered for upgrading existing ${ }^{14} \mathrm{C}$ facilities, or for new instruments for research in the Earth and environmental sciences, primarily for ${ }^{14} \mathrm{C}$ but with the potential also to perform ${ }^{10} \mathrm{Be}$ analyses.

\section{ACKNOWLEDGMENTS}

This work was supported by the Sino Swiss Science and Technology Cooperation and by NSFC40273007 and by the European Community as an Integrating Activity "Support of Public and Industrial Research Using Ion Beam Technology (SPIRIT)” under EC contract no. 227012.

\section{REFERENCES}

Fink D. 2010. AMS-11 in Rome, 2008: past achievements, current and future trends. Nuclear Instruments and Methods in Physics Research B 268(7-8):133442.

Goslar T, Czernik J, Goslar E. 2004. Low-energy ${ }^{14} \mathrm{C}$ AMS in Poznań Radiocarbon Laboratory, Poland. $\mathrm{Nu}$ clear Instruments and Methods in Physics Research B 223-224:5-11.

Klein MG, Mous DJW, Gottdang A. 2006. A compact $1 \mathrm{MV}$ multi-element AMS system. Nuclear Instruments and Methods in Physics Research B 249(1-2): 764-7.

Klein MG, van Staveren HJ, Mous DJW, Gottdang A. 2007. Performance of the compact HVE 1 MV multielement AMS system. Nuclear Instruments and Methods in Physics Research B 259(1):184-7.

Liu K, Ding X, Fu D, Pan Y, Wu X, Guo Z, Zhou L. 2007. A new compact AMS system at Peking University. Nuclear Instruments and Methods in Physics Research B 259(1):23-6.

Müller AM, Christl M, Döbeli M, Kubik PW, Suter M, Synal H-A. 2008. ${ }^{10}$ Be AMS measurements at low energies $(\mathrm{E}<1 \mathrm{MeV})$. Nuclear Instruments and Methods in Physics Research B 266(10):2207-12.

Müller AM, Christl M, Döbeli M, Kubik PW, Suter M, Synal H-A. 2010a. Boron suppression with a gas ionization chamber at very low energies $(\mathrm{E}<1 \mathrm{MeV}) . \mathrm{Nu}$ clear Instruments and Methods B 268(7-8):843-6.

Müller AM, Christl M, Lachner J, Suter M, Synal H-A. 2010b. Competitive ${ }^{10} \mathrm{Be}$ measurements below $1 \mathrm{MeV}$ with the upgraded ETH-TANDY AMS facility. $\mathrm{Nu}$ clear Instruments and Methods B 268(17-18):2801-7.

Müller AM, Döbeli M, Suter M, Synal H-A. 2012. Performance of the ETH gas ionization chamber at low energy. Nuclear Instruments and Methods in Physics
Research B 287:94-102.

Norton GA, Klody GM. 2011. Present trends in the configurations and applications of electrostatic accelerator systems. AIP Conference Proceedings 1336(1): 16-20.

Roberts ML, Culp RA, Dvoracek DK, Hodgins GWL, Neary MP, Noakes JE. 2004. The ${ }^{14} \mathrm{C}$ AMS system at The University of Georgia. Nuclear Instruments and Methods in Physics Research B 223-224:1-4.

Raisbeck GM, Yiou F, Bourles D, Lestringuez J, Deboffle D. 1984. Measurement of ${ }^{10} \mathrm{Be}$ with a Tandetron accelerator operating at $2 \mathrm{MV}$. Nuclear Instruments and Methods in Physics Research B 5(2):175-8.

Stocker M, Bertschinger R, Döbeli M, Grajcar M, Jacob S, Scheer J, Suter M, Synal H-A. 2004. Status of the PSI/ETH compact AMS facility. Nuclear Instruments and Methods in Physics Research B 223-224:104-8.

Sun G, Döbeli M, Müller A M, Stocker M, Suter M, Wakker L. 2007. Energy loss and straggling of heavy ions in silicon nitride in the low $\mathrm{MeV}$ energy range. $\mathrm{Nu}$ clear Instruments and Methods in Physics Research $B$ 256(2):586-90.

Suter M, Huber R, Jacob SAW, Synal H-A, Schroeder JB 1999. A new small accelerator for radiocarbon dating. In: Duggan JL, Morgan IL, editors. 15th International Conference on Application of Accelerators in Research and Industry. 4-7 November 1998. Denton, Texas. American Institute of Physics. p 665-7.

Suter M, Chamizo E, Müller AM, Synal H-A. 2010. The relevance of ion optics for the development of small AMS facilities. Nuclear Instruments and Methods in Physics Research B 268(7-8):722-5.

Synal H-A, Jacob S, Suter M. 2000. The PSI/ETH small radiocarbon dating system. Nuclear Instruments and Methods in Physics Research B 172(1-4):1-7. 